\title{
Self-Control and Loss Aversion in Intertemporal Choice
}

\author{
MARCUS SELART* \\ NIKLAS KARLSSON \\ TOMMY GÄRLING \\ Göleborg University
}

\begin{abstract}
The life-cycle theory of saving behavior (Modigliani, 1988) suggests that humans strive towards an equal intertemporal distribution of wealth. However, behavioral life-cycle theory (Shefrin \& Thaler, 1988) proposes that people use selfcontrol heuristics to postpone wealth until later in life. According to this theory, people use a system of cognitive budgeting known as mental accounting. In the present study it was found that mental accounts were used differently depending on if the income change was positive or negative. This was shown both in a representative nationwide sample of households and in a student sample. Respondents were more willing to cut down on their propensity to consume when faced with an income decrease than to raise it when the income increased. Furthermore, contrary to the predictions of behavioral life-cycle theory, it was found that the respondents adjusted their propensity to consume the most when the income increases or decreases took place immediately. Hence, it is suggested that theories of intertemporal choice (e.g., Loewenstein, 1988; Loewenstein \& Prelec, 1992) provide a better account of the data than does the behavioral lifecycle theory.
\end{abstract}

Several models of household saving behavior have been proposed during this century (e.g., Becker, 1976; Friedman, 1957; Keynes, 1936). As was discussed by Winnet and Lewis (1995), one of the most general may be the life-cycle theory

*Direct all correspondence to: Dr. Marcus Selart, Department of Psychology, Göteborg University, Haraldsgatan 1, S-413 14 Göteborg, Sweden.

Journal of Socio-Economics, Volume 26, No. 5, pp. 513-524

Copyright $\odot 1997$ by JAI Press, Inc.

All rights of reproduction in any form reserved.

ISSN: 1053-5357 
(Modigliani, 1988). In this theory it is implied that people strive towards uniform consumption during the life cycle. Thus people take loans when their income is low because they expect a higher income in the future. On the other hand they save when the income is higher than expected. However, empirical observations have indicated that current income may be a more important factor than the theory predicts. For instance, Courant, Gramlich, and Laitner (1986) report that middleaged households have a higher degree of consumption than younger and older households. To shed further light on this issue, it is important to study how consumption decisions are affected by income changes.

Behavioral life-cycle theory was proposed by Shefrin and Thaler $(1988,1992)$. According to this theory, the current income is of greater importance for consumption than would be predicted from the life-cycle theory. Specifically, this alternative theory attempts to explain why people are unwilling to borrow money when they have a low income. It is argued that people act as if they use three different mental accounts, current spendable income (I), current assets (A), and future income $(F)$. The theory assumes that people are more willing to use the current spendable income for consumption than current assets and more willing to use current assets than future income, that is, if $\mathrm{C}$ is consumption,

$$
1=\partial C / \partial I>\partial C / \partial A>\partial C / D F=0 .
$$

The notion of mental accounts implies that any present or future unit of wealth is not necessarily exchangeable. Thus, the principle of fungibility (McCloskey, 1987) which is basic to the life-cycle theory is violated. Similar assumptions have been made by Carroll and Summers (1987).

To most people immediate consumption is regarded as an attractive alternative to future saving even though the latter would be economically rational. The behavioral life-cycle theory also postulates that people use various devices and heuristic rules to deal with the difficulties of postponing wealth until later in life. Shefrin and Thaler $(1988,1992)$ assumed a structure of preference in two parts as a model of how the internal conflict between rational and emotional aspects are handled. People are supposed to act on the basis of the existence of two inconsistent preferences. One is long-term and rational while the other is short-term and impulsive. They are referred to as the planner and the doer. The planner is directed towards the maximization of life-long utility which implies a reduction of current consumption. The task of the doer, in contrast, is to maximize utility by immediate consumption.

Shefrin and Thaler $(1988,1992)$ found support of their theory in that the propensity to consume a windfall of $\$ 2400$ was greater when it came in increments of $\$ 200$ per month (current spendable income account or I) than when it came in a lump sum (current assets account or A) and in that it was smallest when the $\$ 2,400$ was payable in the future (future income account or F). In a student sample the median consumption expenditures were $\$ 1,200, \$ 785$, and $\$ 0$, respectively. 
One aim with the present study was to attempt to replicate this result. To make it possible to assess whether Shefrin and Thaler's results are generally valid, both a student sample and a representative nationwide sample were used. These samples answered questionnaire questions similar to those used by Shefrin and Thaler.

In the study by Shefrin and Thaler (1988), the current asset account was distinguished from the current spendable income account solely on the basis of how the money was obtained (immediately as a lump sum, incrementally per month, or as a delayed lump sum). However, it seems possible that some alternative explanation is viable. In fact, many theories have been proposed to explain why people in intertemporal choice are unable to choose greater comfort in the long run over a smaller comfort in the short run. It has been suggested by Ainslie (1975, 1982, 1986) that preferences will reverse as a function of the time at which they are made, relative to the time the rewards are available. This can be illustrated by considering two rewards, one smaller which would be received at $t_{1}$ and one larger which would be received at $t_{2}$. The first represents the temptation whereas the second represents some greater reward that would be received further in the future. If the choice is made between the two well in advance, the utility of the second reward is higher. As the time is approached at which the first award is available, its temptation increases so that its utility surpasses that of the later award.

Ainslie $(1975,1982,1986)$ explains violations of delay-independence in terms of the steepness of a function which discounts the utility of a reward. In addition, it has been suggested by Loewenstein (1987) that this steepness is related to several emotional factors which are involved in decisions over time. For instance, when looking forward to pleasant outcomes, we experience what Loewenstein calls "savoring." This emotion is positive, like the experience of the outcome itself. The emotional counterpart for negative outcomes is labeled "dread." According to Loewenstein, some of our emotions are caused by expectations about outcomes, and people have goals concerning these emotions as well as concerning the outcomes themselves.

According to Shefrin and Thaler (1988), saving is supposed to increase if the income is framed in terms of a yearly bonus, as opposed to if it is spread out all over the year. Another prediction can be made from the notion of discounting in intertemporal choice. Here, people are assumed to consume a yearly bonus if it is obtained immediately but not if it is obtained in the future. If it is spread out monthly, people should be less inclined to consume it as compared to if it is paid immediately but more inclined than if it is paid in the future.

In prospect theory (Kahneman \& Tversky, 1979; Tversky \& Kahneman, 1991, 1992) utility is assigned to changes from a reference point which may be the status quo. Building on this theory, Loewenstein and Prelec (1992) assumed that the reference point is sensitive to the wording of the questions that elicit intertemporal tradeoffs. Therefore, they suggest a gain-loss asymmetry for intertemporal choices. They suggest that losses are discounted at a lower rate than gains. It has 
for instance been shown by Loewenstein (1988) that subjects, on average, are indifferent between receiving $\$ 10$ immediately and receiving $\$ 21$ in one year, and also between losing $\$ 10$ immediately and losing $\$ 15$ in one year. The corresponding figures for $\$ 100$ were $\$ 157$ for gains and $\$ 133$ for losses. Dramatic loss/gain asymmetries have similarly been reported by Thaler $(1980,1992)$.

Fischer's (1930) formalization of discounted utility suggests that there should be no difference between a speed-up or a delay of consumption. Accordingly, the discount rates estimated from expediting and delaying gains should be equal and higher than the rates estimated from expediting and delaying losses. However, it was shown by Thaler (1980) that subjects actually may exhibit negative discounting, in that they preferred an immediate loss over a delayed loss of equal value. Hence, Loewenstein and Prelec (1992) predicted that discount rates should be high for expediting a loss and delaying a gain, and lower for expediting a gain and delaying a loss. This prediction gained empirical support (see also Benzion, Rapaport, \& Yagil, 1989). In addition, building on empirical results (Thaler, 1980; Benzion, Rapaport, \& Yagil, 1989) Loewenstein and Prelec claimed that the gainloss asymmetry should be most pronounced for small outcomes.

In a recent study, two versions of a task were accordingly presented to two groups of students (Loewenstein \& Prelec, 1992). The choice options consisted of installment plans for a TV. In both versions respondents (a) had to choose between two alternatives which involved an initial and a later payment, (b) were informed that the initial payment was higher in one of the options whereas the overall payment was higher in the other, and (c) were presented with the same payoffs and delivery times. However, in one of the versions the initial and later payments were framed in terms of their actual values whereas they were expressed in terms of rebates subtracted from a higher price level in the other version. According to the predictions of Fischer's (1930) model, there would be no systematic differences in the responses to the two versions. Nevertheless, a higher fraction of respondents opted for the lowerdiscount option (the one involving greater earlier payments) when the question was framed as a loss rather than as a gain (rebates). Loewenstein and Prelec explained this by suggesting that in the first frame, the large negative outcomes suffered less discounting, which caused people to decide on the basis of total payments. In the second frame the smaller and positive values of the rebates contributed to a relatively high discounting of the delayed outcomes, leading to a preference for the option which offered a greater initial rebate.

A new feature of the present study is that the questions asked by Shefrin and Thaler (1988) were repeated for income decreases. It is not clear what predictions the behavioral life-cycle theory would make in this case. In accordance with the results of Loewenstein and Prelcc (1992), it is predicted that the propensity to cut down on consumption when facing an income decrease (monetary loss) should be less when it comes in decrements per month (I) than when it comes immediately in a lump sum (A). The propensity to cut down on consumption is also expected to 
be less when it comes as a future lump sum $(F)$ than when it comes in decrements per month. Thus, people should adjust the least to future outcomes.

In line with Loewenstein and Prelec (1992), it is further assumed that choices to consume are influenced by the discount rates which should be high for expediting a loss and delaying a gain, while lower for expediting a gain and delaying a loss. It has been pointed out by Shelley $(1993,1994)$ that this asymmetry cannot be attributed to outcome sign alone and that also the direction of change in uutcome timing may be important for the effect. Due to the fact that discount rates are supposed to be low for both expediting a gain and delaying a loss, the adjustment should be higher for losses than for gains in the delayed scenarios, that is, when the gain/loss will occur in the future. The adjustment should on the other hand be higher for gains than for losses when the gain/loss is immediate, that is, if the income change comes in a lump sum. This gives two predictions: (a) The fact that delayed bad outcomes have lower discount rates than delayed good outcomes implies that people will adjust more to the values of bad future outcomes than to the values of good future outcomes; (b) The fact that immediate good outcomes have lower discount rates than immediate bad outcomes implies that people will adjust more to the values of good immediate outcomes than to the values of bad immediate outcomes.

A gain/loss asymmetry has also been reported implying that the balance between gain and loss outcomes is different for immediate than for future events (Prelec \& Loewenstein, 1991). Loss aversion implies that losses loom larger than gains (Kahneman \& Tversky, 1979). In the present context, both on the basis of the gain/loss asymmetry and loss aversion, it is predicted that people will to a larger extent cut down on consumption if facing an income decrease than they are willing to raise it if facing an income increase of the same amount.

Studying the impact on consumption of both income increases and decreases in relation to the use of mental accounts may be illuminating. In particular it may show that the discounting notion is more general and may account for effects of both income increase and decrease. The predictions are thus that consumption is more likely after an immediate rather than an incremental income increase and more likely after an incremental than after a delayed income increase. However, in the case of an income decrease, consumption is foregone when it is immediate rather than decremental and foregone when it is delayed rather than decremental. On the basis of the notion of mental accounts, the behavioral life-cycle theory in contrast predicts that willingness to consume is weakest for a future income increase and strongest for an incremental income increase. Still, no clear predictions seem to follow for income decreases.

\section{METHOD}

In order to test the predictions two mail-back surveys were conducted. One survey was made of a nationwide random sample of 2,000 individuals between 18 and 65 
years old. A second survey was made of a sample consisting of 480 randomly selected undergraduate students at Göteborg University.

In line with standard procedures of the Central Bureau of Statistics of Sweden, two similar questionnaires were constructed for the surveys. The questionnaires included both a module with sociodemographic questions and a module which was designed for hypothesis testing. The only difference between the two versions was that questions about educational background were more elaborate in the version mailed to the representative households.

Based on the survey carried out by Shefrin and Thaler (1988), three questions were designed to be account specific $(I, A, F)$ (see Appendix). These questions were framed both as increases and decreases. For income increases, each question asked the respondents to estimate the marginal propensity to consume out of an income increase which either was SEK $12,000(\$ 1,700)$ or SEK 6,000 (\$850). The three account specific versions differed in how the distribution of the income increase was framed, in terms of when it was distributed and in how large it was. In relation to each version, two questions requested respondents to estimate their consumption propensity for the next month and for the following 11 months, respectively. Participants were presented with three options: (a) to estimate the amount which exceeded the usual degree of consumption; (b) to estimate the amount which fell behind the usual degree of consumption; or (c) to indicate an unchanged degree of consumption.

The income decrease questions asked the respondents to estimate the propensity to cut down on their consumption. The decrease was either SEK 6,000 (\$850) or SEK 3,000 (\$425). ${ }^{1}$ The participants were asked the same questions about their propensity to consume the next month and the following 11 months, respectively. The choice options were also the same.

Income change and amount were treated as between-subjects factors, whereas type of question, or account, was treated as a within-subject factor. This means that all respondents answered the three questions tapping different accounts. Moreover, an approximately equal number of respondents in different subgroups answered the questions for income increases or decreases. Similarily, questions involving different amounts were answered by diffferent subgroups.

Initially, the respondents in each sample received a questionnaire with a letter explaining the purpose of the study. Three days later reminders were mailed to all members of the samples. Two weeks later new reminders were mailed to nonrespondents including a new copy of the questionnaire. Those who received this second reminder were also offered compensation in the form of a lottery ticket worth $\$ 3$. Still another two weeks later, nonrespondents were contacted by telephone and again reminded. A new questionnaire was sent to those who agreed to respond. 


\section{RESULTS}

The data sets consisted of usable responses from $50 \%$ of the nationwide sample (996 respondents) and 58\% of the student sample (277 respondents). Analyses indicated that the missing respondents did not systematically differ from those who responded. The participants who responded after two reminders did not differ reliably with respect to age, gender, and income characteristics from those who responded immediately or after one reminder. In the nationwide sample, participants and nonparticipants did not differ much with respect to age (41.1 years and 41.3 years, respectively). A $t$-test confirmed that this difference was not significant, $t_{(1983)}=.40, p=.55$. Regarding the gender distribution $50.5 \%$ were men and $49.5 \%$ were women, whereas the corresponding figures for nonparticipants were $48.8 \%$ and $51.2 \%$. These proportions did not differ from chance $\left(\chi^{2}=.57\right.$, $p<.45)$. The mean income level reported by participants was $\$ 21,800(\$ 25,700$ for males and $\$ 17,570$ for females) which is close to the nationwide average.

Tests were made of how actual income and asset position influenced the propensity to adjust to income changes ${ }^{2}$ in the nationwide sample. An ANOVA revealed that account interacted neither with actual income nor asset position. In fact, the respondents' propensities to consume showed the samc account-specific rank order independent of socio-economic status (actual income $\times$ asset position). However, separate one-way ANOVAs revealed reliable effects for both income position, $F(2,751)=8.76, p<.0001$, and asset position, $F(2,491)=10.82$, $p<.0001$. Thus, respondents with low income and little assets to a higher extent adjusted to income changes.

The estimates of total consumption was calculated for each subject and condition according to the equation $11 X+Z$, where $X$ denotes the estimate for the next month and $Z$ the estimate for each of the following 11 months. In line with the results of Winnett and Lewis (1995), it was found in the nationwide sample that a large proportion of respondents from both samples reported that they would not change their consumption. In the income increase condition $41.7 \%$ of the respondents indicated that they would increase consumption, $58 \%$ that they would not change it, and $0.3 \%$ that they would decrease it. In the income decrease condition $67 \%$ indicated that they would decrease consumption, $32 \%$ that they would not change it, and $1 \%$ that they would increase it. Hence, because of the positively and negatively skewed distributions, the estimates were recoded as increases or decreases of consumption. If a respondent revealed a total increase this was coded as 1 , whereas a total decrease was coded as -1 . If the respondent on the other hand had chosen not to change in both questions, this was coded as 0 . In the incomedecrease condition the signs were reversed.

The mean proportions of adjustments are given in Table 1 for each income change condition and sample. As may be seen, in both samples the respondents were most willing to change their propensity to consume if an income increase came in a lump sum (A) and not in increments per month (I). ${ }^{3}$ Furthermore, the 
respondents were least willing to consume when the income increase came in a future lump sum (F). The results were different for an income decrease: In both samples respondents were less willing to forego consumption when the income decrease came in decrements and most willing when it came in a future or immediate lump sum. A sample (2) by income change (2) by account (3) analysis of variance (ANOVA) with repeated measures on the last factor showed that the interaction between income change and account was significant, $F(2,2118)=$ $125.67, p<.0001$. In addition, adjustments were larger for an income decrease than an income increase, as substantiated by a reliable main effect of income change, $F(1,1059)=59.61, p<.0001$. It was also larger in the student sample than in the nationwide sample, $F(1,1059)=29.84, p<.0001$. In addition, there was a significant interaction between sample and account, $F(1,1059)=5.31$, $p<.05$, indicating that students were more willing to adjust to a future lump sum than respondents in the nationwide sample.

\section{DISCUSSION}

The behavioral life-cycle theory (Shefrin \& Thaler, 1988, 1992) assumes that people use mental accounts to be able to postpone consumption until later in life. An important implication is that the propensity to consume an income increase should be greater when it comes in increments per month than when it comes in a lump sum, and that it should be smallest when it is expected as a future lump sum. Shefrin and Thaler received support for this implication in a sample survey of students. The results of the present study were different. Both a student sample and a nationwide sample showed that willingness to consume was stated to be higher when respondents imagined that an income increase would be received immediately as a lump sum. This outcome was predicted from theories of intertemporal choice (Loewenstein, 1988; Loewenstein \& Prelec, 1992) which assume that future outcomes are positively discounted. Consistent both with the predictions from the behavioral life-cycle theory and theories of intertemporal choice, respondents were least willing to consume when they imagined they would receive an income increase as a future lump sum.

In the present study, an extension of Shefrin and Thaler's results (1988) was made in that the consumption questions were also asked for income decreases. In this case it is unclear whether the behavioral life-cycle theory makes any definite predictions. From theories of intertemporal choice (Loewenstein, 1987; Loewenstein \& Prelec, 1992), it was predicted that consumption would be forgone more after an immediate income decrease than after a decremental income decrease. The results were consistent with this prediction. However, they also showed that a decremental income decrease did not differ from a future income decrease which came in a lump sum. This may be interpreted in line with other recent findings indicating that losses are not as heavily discounted as gains (e.g., Loewenstein, 
Table 1. Mean Proportions of Adjustments to Income Changes in the Nationwide and Student Sample Related to Income Change and Mental Account

\begin{tabular}{lll}
\hline & Nationwide Sample & Student Sample \\
\hline Income increase & & \\
$\begin{array}{l}\text { \$1,700/year } \\
\text { Current spendable income (1) }\end{array}$ & .46 & .84 \\
$\quad$ Current assets (A) & .55 & .82 \\
$\quad$ Future income (F) & .13 & .20 \\
\$850/year & & \\
$\quad$ Current spendable income (I) & .40 & .61 \\
$\quad$ Current assets (A) & .53 & .79 \\
Future income (F) & .10 & .15 \\
Income decrease & & \\
\$850/year & .64 & .61 \\
$\quad$ Current spendable income (I) & .77 & .76 \\
$\quad$ Current assets (A) & .72 & .71 \\
$\quad$ Future income (F) & & \\
\$425/year & .42 & .63 \\
$\quad$ Current spendable income (I) & .68 & .80 \\
$\quad$ Current assets (A) & .57 & .75 \\
$\quad$ Future income (F) & & \\
\hline
\end{tabular}

1987; Loewenstein \& Prelec, 1992; Thaler, 1980). Nevertheless, the idea of mental accounting was supported by the fact, that there were no interactions between account and actual income. For instance, the respondents' propensities to consume showed the same account-specific rank order independent of socioeconomic status.

Another prediction which was borne out was that in both samples adjustments were greater to income decreases than to income increases. This was predicted both from the gain/loss asymmetry which suggests that gains are discounted more heavily than losses (e.g., Loewenstein, 1987; Loewenstein \& Prelec, 1992) and from loss aversion which implies that losses are weighted more heavily than gains (Kahneman \& Tversky, 1979; Tversky \& Kahneman, 1991, 1992). It should be noted that the asymmetry was observed even though the absolute amount of the income decrease was higher than the amount of the income increase, consistent with the value function in prospect theory (see note 1). Thus, the observed asymmetry was probably not accounted for by loss aversion alone.

It is also noteworthy that the respondents seemed most willing to adapt to the values of the loss outcomes in both the delayed and the immediate scenario (equivalent to the $\mathrm{F}$ and $\mathrm{A}$ accounts), although this tendency was clearest in the former case. These results support the prediction that (a) delayed losses have lower discount rates than delayed gains, but violate the prediction that (b) immediate gains have lower discount rates than immediate losses (both predictions from Loewenstein \& Prelec, 1992). They hereby underline that loss aversion is a salient feature of intertemporal choice. 
In general, the results were very similar for the student sample and the representative nationwide sample. A difference was that the students were more willing to adjust to an income change, and in particular to an income increase. A possible explanation is that consumption is more attractive to students who in general consume less than the average consumer.

In conclusion, the results failed to completely replicate the results of Shefrin and Thaler (1988). It also showed that the respondents act differently when consumption questions are asked in the context of income decreases. It is suggested that theories of intertemporal choice (Loewenstein, 1988; Loewenstein \& Prelec, 1992) in some respects could explain the results better than the behavioral lifecycle theory (Shefrin \& Thaler, 1988, 1992). This suggests that although people use mental accounting in everyday life, the phenomenon is in need of a more thorough analysis concerning its properties and functions (Henderson \& Peterson, 1992; Ranyard, 1995).

Acknowledgments: The study was financially supported by grant \#94-0086:2C to the last author from the Swedish Council for Social Research. A previous version of the paper was presented at the 20th conference of the International Association for Research in Economic Psychology (IAREP), Bergen, Norway, August 2-5, 1995.

Appendix. Questions and Response Options used in the Quetsionnaire

Hypothesis-testing questions for income increase

1. (l) You have received a permanent income increase through your work to the amount of $\$ 142$ per month after taxation.

2. (A) You have received a temporary income increase through your work to the amount of $\$ 1,700$ after taxation. It will be paid in a lump sum this month.

3. $(F)$ You have received a temporary income increase through your work to the amount of $\$ 1,700$ after taxation. It will be paid in a lump sum in 12 months, and will until then be placed in an interest bearing account.

Hypothesis-testing questions for income decrease

1. (I) You have received a permanent income decrease through your work to the amount of $\$ 71$ per month after taxation.

2. (A) You have received a temporary income decrease through your work to the amount of $\$ 850$ after taxation. It will be deducted as a lump sum this month.

3. $(F)$ You have received a temporary income decrease through your work to the amount of $\$ 850$ after taxation. It will be deducted with interest as a lump sum in 12 months.

Questions and response options for both types of income change

Do you think that during the next month you will consume: $\$$ more than usual $\$$ less than usual $\$$ As much as usual

Do you think that during the following 11 months you will consume: $\$$ more per month than usual $\$$ less per month than usual $\$$ As much as usual

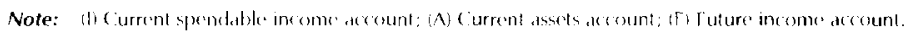




\section{NOTES}

1. Since the value function of prospect theory (Kahneman \& Tversky, 1979; Tversky \& Kahneman, 1991, 1992) is approximately twice as steep for losses than for gains, the amounts in the decrease condition would render the value about equal.

2. If a respondent's annual income fell below $\$ 17,000$, it was categorized as low; if it ranged between $\$ 17,000$ and $\$ 34,000$, as moderate; and if it exceeded $\$ 34,000$, as high. The reported asset positions were categorized in a similar way: If the reported asset position of a respondent fell below $\$ 7,000$, it was categorized as low; If it ranged between $\$ 7,000$ and $\$ 28,500$ as moderate, and if it exceeded $\$ 28,500$ as high.

3. If the data for the student sample had been aggregated as medians as Shefrin and Thaler (1988) did, the results would have been similar in the income-increase condition. This was, however, not true for the representative sample.

\section{REFERENCES}

Ainslie, G. (1975). Specious reward: A behavioral theory of impulsiveness and impulse control. Psychological Bulletin, 82, 463-509.

Ainslie, G. (1982). A behavioral economic approach to the defense mechanisms: Freud's energy theory revisited. Social Science Information, 21, 735-779.

Ainslie, G. (1986). Beyond microeconomics: Conflict among interests in a multiple self as a determinant of value. In J. Elster (Ed.), The multiple self (pp. 133-175). Cambridge: Cambridge University Press.

Becker, G.S. (1976). The economic approach to human behavior. Chicago: Chicago University Press.

Benzion, U., Rapaport, A., \& Yagil, J. (1989). Discount rates inferred from decisions: An experimental study. Management Science, 35, 270-284.

Carroll, C., \& Summers, L.H. (1987). Why have private savings rates in the United States and Canada diverged? Journal of Monetary Economics, 20, 249-279.

Courant, P., Gramlish, E., \& Laitner, J. (1986). A dynamic micro estimate of the life cycle model. In H.G. Aaron \& G. Burtless (Eds.), Retirement and economic behavior. Washington, DC: Brookings Institute.

Fischer, I. (1930). The theory of interest. New York: Macmillan.

Friedman, M. (1957). A theory of consumption function. Princeton, NJ: Princeton University Press.

Henderson, P.W., \& Peterson, R.A. (1992). Mental accounting and categorization. Organizational Behavior and Human Decision Processes, 51, 92-117.

Kahneman, D., \& Tversky. A. (1979). Prospect theory: An analysis of decision under risk. Econometrica, 47, 263-291.

Keynes, J.M. (1936). The general theory of employment, interest, and money. London: Macmillan

Loewenstein, G. (1987). Anticipation and the value of delayed consumption. Economic Journal, 97. 666-684.

Loewenstein, G. (1988). Frames of mind in intertemporal choice. Managerment Science, 34, 200214.

Loewenstein, G., \& Prelec, D. (1992). Anomalies in intertemporal choice: Evidence and interpretation. In G. Loewenstein \& J. Elster (Eds.), Choice over time. New York: Russell Sage Foundation.

McCloskey, D. (1987). Fungibility. In J. Eatwell, M. Milgate, \& P. Newman (Eds.), The new palgrave: A dictionary of economics (p. 444). London: Macmillan. 
Modigliani, F. (1988). The role of intergenerational transfers and life cycle saving in the accumulation of wealth. Journal of Economic Perspectives, 2, 15-40.

Prelec, D., \& Loewenstein, G. (I9YI). Decision making over time and under uncertainty: A common approach. Management Science, 37, 770-786.

Ranyard, R. (1995). Mental accounts in financial decision making: A cognitive-psychological analysis. In E. Nyhus \& S.V. Troye (Eds.), Frontiers in economic psychology: Proceedings of the 20th IAREP-conference, Bergen, Norway (pp. 615-636). Bergen: NHH Press.

Shefrin, H.M., \& Thaler, R. (1988). The behavioral life-cycle hypothesis. Economic Inquiry, 26, 609-643.

Shefrin, H.M., \& Thaler, R. (1992). Mental accounting, saving, and self-control. In G. Loewenstein \& J. Elster (Eds.), Choice over time (pp. 287-330). New York: Russell Sage Foundation.

Shelley, M.K. (1993). Outcome signs, question frames, and discount rates. Management Science. 39, 805-815.

Shelley, M.K. (1994). Gain/loss asymmetry in risky intertemporal choice. Organizational Behavior and Human Decision Processes, 59, 124-159.

Thaler, R. (1980). Toward a positive theory of consumer choice. Journal of Economic Behavior and Organization, 1, 39-60.

Thaler, R. (1992). The winner's curse: Paradoxes and anomalies of economic life. New York: Free Press.

Tversky, A., \& Kahneman, D. (1991). Loss aversion in riskless choice: A reference-dependent model. The Quarterly Journal of Economics. 106, 1039-1061.

Tversky, A., \& Kahmeman, D. (1992). Advances in prospect theory: Cumulative representation of uncertainty. Journal of Risk and Uncertainty, 5, 297-323.

Winnett, A., \& Lewis, A. (1995). Household accounts, mental accounts, and savings behavior: Some old economics rediscovered? Journal of Economic Psychology, 16, 431-448. 